\title{
ADMINISTRAÇÃO DE PESSOAL-
}

\section{Formação Profissional: Fórmulas Ideais}

\section{EstaNisLAu Fischlowitz}

Impressionado com o deficit sempre crescente da mão-de obra especializada, - que se torna agudo quando computamos, separadamente, os grupos elitários técnicos, - o autor considera urgente acelerarmos, com a mais alta prioridade, a formação profissional de mão-de-obra, cm todos os niveis sob pena de legarmos às gerações que se vêm formando. as maiores dificuldades na demanda lo primeiro
emprêgo.

Um grande passo para a equação do problema. seria a criação de um órgâo de alto gabarito no Ministério do Trabalho e Previdência Social, com a superintendência de tôda a orientação e contrôle ciplinar e racionalizar o toroblem podêres para distegral da mão-de-obra.

Ao mesmo tempo, seria incrementado e facilitado, junto a emprêsas e sociedades de economia mista, a formação técnica profissional, de que tanto
necessita o Pais.

O desempenho do S.E.N.A.I. e S.E.S.C., nesse sentido, deveria ser também mais prestigiado e estimulado, propiciando-se àqueles organismos os meios necessários para a execuşão de seus programas edu-
cacionais.

$\mathrm{P}$

ARECE lugar comum ressaltar a posição de particular destanômico e social processos de equilibrado desenvolvimento ecoprofissional. 
Com efeito, tal investimento no "capital humano" reune os maiores requisitos, simultâneamente, tanto sob o prisma da expansão da riqueza nacional, quanto sob o ponto-de-vista de bemestar social, isto é, de fomento dos fenômenos benéficos de mobilidade social: ascensão vertical de todos quantos integram as classes econômicamente débeis e socialmente dependentes da sociedade.

Entre as "reformas de base", merecem, pois, tratamento de mais alta prioridade, as providências subordinadas ao propósito de organizar, de modo mais eficiente possivel, a acelerada formação profissional em massa da mão-de-obra, em todos seus níveis: alto, médio e baixo, assim como em todos os setores da economia e em relação a todos os grupos etários.

No momento em que, por vários motivos, que são de conhecimento de todos, se nos deparam consideráveis dificuldades no caminho rumo ao incremento, em escala desejável, das inversões no "capital material", ofereceria, pois, as maiores vantagens, o deslocamento do centro de gravidade, na aplicação dos disponiveis recursos nacionais, para a expansão e o aprimoramento das qualificações técnico-profissionais dos trabalhadores, que, ainda, não podem oferecer ao setor empresarial mais do que seu mero esfôrço braçal.

Tais inversões, dedicadas à ampliação da rêde escolar de ensino técnico-profissional e ao aperfeiçoamento dos serviços de aprendizagem "institucional" e "empresarial", apresentam, comprovadamente, o mais elevado valor, rendendo, a longo prazo, "juros" plenamente compensadores. Condicionando trabalho produtivo e rendoso dos beneficiados pelos respectivos programas durante tôda a sua longa vida econômicamente ativa, portanto reunindo condições extraordinárias de "durabilidade", agem, ao mesmo tempo, como poderoso fator multiplicador sôbre todos os demais elementos da produção. Admite-se, aliás, geralmente, que o aumento da mão-de-obra adestrada assegura, por si só, incremento do rendimento anual dos setores de economia, assim fortalecidos, em $6 \%$ a $12 \%$ do custo dos respectivos programas de formação profissional.

Não nos parece fora de propósito, relembrar, em breve, o papel desempenhado pelas realizações enquadradas na conceituação mais lata e polivalente de formação profissional, encarado, separadamente, sob o ângulo econômico e social.

A observação atenta do transcurso dos processos econômicos pròpriamente ditos, na última fase de evolução da economia brasileira, no setor secundário e terciário, $\left({ }^{\star}\right)$ manifesta-nos, com

( $^{\star}$ Usamos aqui os têrmos de discriminação da economia, que se devem a iniciativa do famoso economista Collin C $\mathrm{C}_{\text {LARK. }}$ 
clarividência, que nada deixa a desejar, a existência de nevrálgicos: pontos de estrangulamento relacionados com as acentuadas dis. crepâncias entre os escalões de mão-de-obra oferecidos e procurados.

$\mathrm{Na}$ economia industrial, comercial e de transportes, sujeita ao crescente impacto da revolução tecnológica e organizacional contemporânea, com cada vez maior racionalização, mecanização e até, principios de automatização, surgem, fatalmente, novas e muitas mais rigorosas exigências quanto ao aproveitamento, sobretudo, da mão-de-obra altamente especializada e técnica, porém também qualificada, aliás no sentido afastado de seus conceitos. tradicionais, e mesmo, semi-qualificada, todavia, por seu turno, com requisitos muito mais elevados quanto a seu preparo vocacional. Ao mesmo tempo diminui, em ritmo impressionante, a demanda de mão-de-obra simples, cujas oportunidades infimas de empregabilidade estão fadadas a provocar o futuro surto maciço de desemprêgo. $\left({ }^{\star *}\right)$

Ora, acompanhando-se a situação, de lado de "anverso da medalha", isto é a oferta de mão de -obra, não podemos deixar de anotar que continua seguindo rumos exatamente opostos, condicionando as mais graves distorções na composição da nossa
mão-de-obra.

$\odot$ que se verifica, à luz de tôdas as pesquisas atinentes ao estado do mercado de trabalho nacional, diga-se de passagem. muito incompletas e fragmentárias, são deficits agudos no tocante a grupos elitários técnicos (engenheiros e quimicos), e gerenciais, com disponibilidade igualmente deficiente dos contingentes com grau intermediário de instrução e treinamento (técnicos industriais, laboratoristas, pessoal encarregado de análise, desenhistas, cargos de contabilidade industrial, etc.) e lacunas, maiores ou menores, no concernente à mão-de-obra operária qualificada e semi-qualificada, aproveitável na produção e conservação, no parque de trans.
porte, nas vendas etc.

Muito pelo contrário, apresenta ábundância extraordinária a oferta da mão-de-obra não qualificada, cujas reservas, pràticamente inesgotáveis, aumenta, ainda mais, o permanente e extremamente forte influxo nos grandes centros urbanos dos migrantes nacionais, de proveniência, particularmente da zona rural, porém também das menores aglomerações citadinas do interior. $\left({ }^{* \star}\right)$

$\left.{ }^{* *}\right)$ Os rumos acima delineados, quanto a emprêgos oferecidos, encontram comprovação integral nos levantamentos periódicos da indústria, a que
p:ocede o S.E.N.A.I., D.R. de São Paulo.

$\left(^{\star * *}\right)$ Convém consultar Estanislau Fischlowitz Internas en Brasil, Revista Mexicana de Sociologia, $\mathrm{n}^{2} 3$ de Las Migraciones. 
Tudo o que precede, lança, desde já, muita luz sôbre os -aflitivos aspectos sociais dos desajustes acima esboçados, quanto à configuração qualitativa da parte preponderante da mão-de-obra nacional.

O que merece, nessa ordem de idéias, apreciação atenta, são: yular.

a) possibilidades de consecução do emprêgo estável e re-

b) oportunidades que se oferecem aos trabalhadores no concernente à obtenção dos razoáveis niveis salariais, necessários à satisfação de suas necessidades condignas de consumo e, enfim,

c) condições de ascensão maleável dêles a cargos mais elevados, dentro da classe média assalariada, cargos de maior responsabilidade e de relativamente mais altos rendimentos de trabalho.

Ora, o cenário atual, apreciado sob todos êsses três pontosde-vista, leva às conclusões um tanto desanimadoras quanto aos efeitos do atual adestramento precário da mão-de-obra.

No mercado de trabalho aparecem, desde já, ao lado do subemprêgo, cuja incidência manifesta rumos ascensionais, bolsões isolados de desemprêgo crônico, cuja causalidade se deve, entre vários outros fatôres (ciclo-conjuntural adverso, instabilidade monetária, excessivo intercâmbio populacional etc.) também ao despreparo vocacional dos consideráveis contingentes de mão-de-obra, na parte mor, ainda sempre meramente braçal. Pode-se, quase axiomàticamente, antecipar a agravação do chomage nas próximas décadas, sobretudo no que diz ao "desemprêgo inicial" da nova geração, cujos grupos numerosos ingressam, todos os anos, no mercado de trabalho, em busca do primeiro emprêgo remunerado, e cuja absorção pela economia de trabalho acarreta crescentes dificuldades, dadas as suas deficientes qualificações profissionais. Eis um reflexo fatal da explosão demográfica, $\left({ }^{\star}\right)$ evidenciada pelo Censo de 1960 (taxa anual geométrica de aumento vegetativo, igual, no último período intercensitário, a $3,11 \%$ superior aos coeficientes dos dois decênios, anteriores: $2,38 \%$ no último e $1.51 \%$ no, penúltimo). Com efeito, o acelerado aumento populacional transforma a pirâmide etária, com incremento das faixas de idade menor, (ao que parece, no momento cêrca de $45 \%$ do total!), cujos componentes passam a agudizar a demanda de emprêgos, sem apresentarem, na sua maioria esmagadora, nem as condições qualitativas elementares, necessárias ao exercício do trabalho produtivo.

$\left(^{\star}\right)$ Convém consultar Estanislau Fischlowitz - Dinamismo Popula. cional e Desenvolvimento Econômico, Sintese. Taneiro-março de 1962. 
Quanto à remuneração, prevalecem padrões bastante reduzidos. de salário real, sendo que em vários setores da economia o salário médio pouco excede os niveis correspondentes às taxas de salário mínimo. Em tese, pode-se esperar a melhor remuneração quando os proletários, que apenas dispõem da fôrça física, va. lendo-se de recursos de educação e formação profissional, passam. a exercer trabalho semi-qualificado e qualificado, podendo pro. duzir mais e melhor. De um modo geral, a realidade corresponde a tais expectativas; entretanto, cumpre destacar que a evolução nesse sentido não se processa de maneira desejável, em virtude da forte influência niveladora, exercida sôbre o "leque de salários" pela instituição de salário mínimo. (*) Como é natural, tais distorções transitórias prestam-se a serem sanadas mediante reajustamento do intervencionismo salarial público, particularmente sob a forma de criação do salário móvel, aplicável, indistintamente, a tôdas as classes de salário, capaz de incentivar a for-
mação profisisonal.

O mesmo quadro oferece-se-nos no tocante aos processos de avanço social da classe proletária, aliás, intimamente entrosados com o problema acima aludido. Superando, vitoriosamente, as rígidas barreiras, existentes nesse particular, vários trabalhadores logram ascender a cargos intermediários da hierarquia industrial, penetrando, aos poucos, na classe média assalariada. Se, como parece certo e seguro, é preciso intensificar muito mais tais fenômenos salutares de mobilidade social, o nıeio principal que poderá assegurar a consecução de tal meta, consistiria na ampliação dos recursos não sòmente de educação geral, como, sobretudo, de formação profissional, postos, Isob tôdas as suas modalidades, à
disposição da classe trabalhadora.

\section{II}

Esse resumo dos aspectos econômicos e sociais do atual pa norama do Brasil leva às conclusões nìtidamente favoráveis à maior expansão e ao aperfeiçoamento máximo de todos os pro. profissional.

Antes de esboçar o balanço real dêsses programas, como se nos apresenta em 1963, como natural ponto de partida para as

(*) Tal impacto do salário minimo fica comprovado pela pesquisa sôbre os salários das 22 profissões representativas do parque industrial paulista, desajustes, na elevação muito maior entre dos nrofissionais não-qualificados e menor 1949,1951 e 1961 da remuneração lhadores qualificados. 
futuras providências nacionalizadoras nessa matéria, cumpre-nos. salientar que dificilmente tais providências poderiam atingir grau desejável de eficiência funcional, se não fôssem preenchidas duas. condições básicas.

Em primeiro lugar, a orientação específica dos respectivos. programas, quanto à seleção ocupacional, profissional e etária, dos. grupos a serem treinados, das técnicas a serem utilizadas para. tal fim e do prazo de duração das realizações de que se pretende lançar mão, tem que depender das previsões acertadas no tocante às necessidades econômicas que deverão ser asim atendidas.

Sem projeções, baseadas na observação estatística das tendências atuais e nos prognósticos objetivos, relativos ao provável transcurso futuro dos processos econômicos e do dinamismo demográfico, tudo o que se quiser fazer, nesse particular, enfrentaria o risco contraproducente de divorciamento com a realidade. $\mathrm{E}^{\prime}$ óbvio que os programas de formação profissional, capazes de surtir todos os efeitos almejados, não podem ser, em hipótese alguma, agarrados ao atendimento das necessidades da época passada, e, mesmo, presente. $E$ isto também em virtude da natural decalagem do tempo entre o início ou a revisão dos respectivos programas e seu rendimento final. Na grande maioria dos países empresta-se, por conseguinte, a maior importância à elaboração, a mais aprimorada possivel, de tais projeções, de amplitude e profundidade, compativeis com seu papel de responsabilidade inconteste. A guisa de mero exemplo, cumpre destacar os interessantes trabalhos nesse sentido, levados a efeito dentro do famoso "Plano de Mediterrâneo". Na mais ampla órbita internacional, merecem ser realçadas as valiosas contribuições para êsse fim, consubstanciadas nas recomendações do grupo de peritos, de alto gabarito, recém-convocados pela Repartição Internacional do Trabalho. ( ${ }^{\star}$ )

Ora, não podem passar despercebidos flagrantes claros que se nos oferecem nesse particular, no Brasil. Nas condições de fluída conjuntura econômica, agravada pela instabilidade monetária, a previsão acertada dos rumos econômicos, mesmo a curto e médio prazo, acarreta, é preciso reconhecê-lo, dificuldades consideráveis, ao passo que não existem em relação aos prognósticos populacionais, desde que fôssem definitivamente apurados os resultados do Censo de 1960 . Contudo, por motivos ignorados, foi suspenso, no ano passado, o funcionamento do Grupo de Estudos de Mão-de-Obra (Gemo), constituido, junto ao I.N.I.C., pelo Decreto $n^{\circ} 51.251$ de 24 de agôsto de 1961, e que conseguiu, concentrar em suas mãos o rico acervo de documentação e de

(*) Réunión d'Experts sur l'Evaluatión des Besoins en Matière de MainD'Ouvre et de Formatión pour le Développement Économique (1-10 de outubro de 1962). 
estudos, indispensável para o cumprimento dessa tarefa. Em falta, na estrutura da administração federal, de um órgão especializado, encarregado da politica de mão-de-obra, nada se faz, no momento, para preencher tais lacunas. Convém apenas assinalar dois excelentes estudos, atinentes a essa matéria, e preparados, em 1962, pela Comissão Nacional de Planejamento (Decretos $n^{2} 51.152$ de 5 de agôsto de 1961 e $n^{\circ} 154$ de 17 de setembro de 1961 . (**)

Por outro lado, a programação da formação profissional poderia corresponder integralmente a seus importantes objetivos, apenas quando estiver devidamente entrosada com planos, a longo prazo, de equilibrado desenvolvimento econômico e social. Nas grandes obras de planejamento costuma-se, pois, via de regra, incluir diretrizes atinentes à valorização dos recursos humanos.

Ora, enquanto não faltam entre nós planos desenvolvimen$t$ stas de indole regional, cuja principal, relativa ao Nordeste e afeta à S.U.D.E.N.E., não deixa de atacar vários aspectos relacionados com o aproveitamento da mão de obra daquela desprivilegiada área, não possuimos, ainda, na realidade, tais planos de âmbito nacional. O Plano Trienal, a primeira tentativa nesse sentido, aliás, ao que parece, em grande parte, já posto de lado, nâo dispensa, como é notório, maior atenção aos aspectos sociais
de desenvolvimento.

Seja como fôr, não se pode prestar à interpretação controvértida a crescente agravação do panorama nacional, quanto a problemas, quantitativos e qualitativos, de mão-de-obra, aliás,
intimamente entrelaçados entre si.

Pois, bem, não existe ainda, obra, capaz de equacioná-los. Os principios politica de mão-deapenas vagamente no horizonte. As realizacões delineiam-se tal politica, ampla e dinâmica, não poderão ficar construtivas de diretrizes planejadoras, eis que, de contrário ficar dissociadas das dizer, suspensas no ar. E, como é natural, o intervencion assim estatal no setor de mão-de-obra pressupõe, antes de criação no serviço público de uma entidade central, destinada a promover tais providências, com tôda ênfase deslocada para a
coordenação de vários organismos, públicos, semi-estatais e semi-
privados, que atuam, isoladamente, privados, que atuam, isoladamente, nessa matéria.

O que urge, por conseguinte, é a criação imediata, no plano de administração pública federal, de um órgão, colocado no mais alto nivel ministerial, $\left({ }^{*}\right)$ dotado de necessários recursos e podê$\left({ }^{* *}\right)$ Cumpre realçar, aqui, particularmente, o Plano Demográfico e o
Estudo das Migrações, de 1962. $\left(^{*}\right)$ Não nos parece satisfazer plenamente a solução (Departamento de
Mão-de-Obra e Salário), consubstanciada no projeto de reestruturação do
Ministério do Trabalho e Previdência Social, elaborado pera tuida pelo Decreto $\mathrm{n}^{\circ} 51.044$, de 25 de julho de 1961 . 
res, e a que incumbiriam providências racionalizadoras e disciplinadoras no setor de mão-de-obra sensu lato, inclusive no tocante à elaboração das projeções acima aludidas, e que, assim, possa contribuir para a extensão à mão-de-obra das futuras e mais polivalentes medidas de planificação nacional.

\section{III}

Cabe-nos apresentar, a seguir, o balanço, o mais sumário possivel, das realizações brasileiras, nesse assunto, relacionadas, sobretudo com o setor-chave: indústria nacional, dentro do trinômio: 1) sistema de educação pública; 2) serviços sociais de aprendizagem (particularmente S.E.N.A.I., com algumas alusões à sua entidade irmã: S.E.N.A.C.), acompanhadas por órgãos com finalidades afins, como seja a C.B.A.I., $\left(^{\star \star}\right)$ e, enfim; 3) formação profissional infra-empresarial. Na respectiva análise propomo-nos distribuir, equitativamente, as suas respectivas luzes e sombras.

No concernente à rêde de ensino público, merecem exame todo particular, por uma lado, os subsidios nesse sentido, dos centros universitários, quanto à formação tanto dos quadros técnicos elitários, engenheiros e químicos, como de pessoal altamente qualificado gerencial, e, por outra parte, dos estabelecimentos de ensino médio de caráter técnico e profissional.

Quanto à produção anual de engenheiros, vem sendo considerada com unanimidade, deficitária (mais ou menos 2.000 formados por ano), tendo sido, por conseguinte, sugerido em 1962 . pela comissão, presidida pelo Diretor de Ensino Superior do Ministério da Educação e Cultura a alteração dos currículos das competentes escolas de engenharia, no sentido de possibilitar-a formação anual acelerada, mediante cursos de 3 anos, de 3.000 engenheiros de operação, ao lado de 3.000 engenheiros plenamente qualificados em cursos de 5 anos. $\left({ }^{*}\right)$

No tocante à business administration pròpriamente dita, é mister salientar que nos últimos anos surgiram, pela primeira vez, numerosas escolas e cursos especiais, dentro e fora da rêde universitária, que se destinam à constituição do pessoal gerencial de nível elevado, sendo que seria ainda prematura a tentativa no sentido de apreciar seu rendimento global.

$\left({ }^{\star \star}\right)$ Entidade sui generis brasileiro-americana, criada pela Recomendação $\mathrm{n}^{\circ} \mathrm{XV}$ da XV Conferência Interamericana, realizada entre 25 de setembro e 4 de outubro de 1943.

( $\left.{ }^{\star}\right)$ Cumpre ressaltar os interessantes subsidios para o exame integral dêsse problema, prestados pelo Grupo recém constituido na Fundação Getúlio Vargas e liderado pelo Prof. Joaquim Faria Góes. 
No que diz respeito à atuação dos estabelecimentos de ensino técnico de nivel médio, cumpre examinar os dados estatisticos, relativos à sua matrícula, em 1962. Havia, naquêle ano, 84 ginásios e 94 colégios industriais, com matrícula total igual a 36.500 alunos (24.328 inscritos nos ginásios e 12.212 - nos colégios dessa indole).

Abrindo parêntese, convém salientar a discrepância entre o desenvolvimento moderado dos ciclos didáticos de ensino médio industrial, e a grande expansão dos estabelecimentos de ensino comercial, aliás, com prevalência de escolas privadas, assim como o angustiante subdesenvolvimento do ensino técnico agrícola.

Em conexão com a lei de Diretrizes e Bases, programa-se a expansão substancial dêsses estabelecimentos, sobretudo no concernente a ginásios industriais. Entretanto, em virtude de seu subequipamento técnico - amplitude limitada de seus cursos e descoordenação com o setor empresarial, não se deve apreciar de modo excessivo os serviços que prestam, no atendimento das necessidades pessoais da nossa economia.

Passamos a expor os resultados de atuação das entidades semi-privadas, patronais, de caráter institucional e coletivo, constituídas, de início, mediante Decreto-lei n’ 4.048 de 21 de janeiro de 1942, quanto ao S.E.N.A.I., e, a seguir, por meio de Decreto-lei $n^{9} 8.622$ de 10 de janeiro de 1946 , no que diz respeito ao
S.E.N.A.C.

Cumpre-nos tornar bem patente que, desempenhado no Brasil e no o papel de particular destapelo S.E.N.A.I., primeira entidade Hemisfério Ocidental inteiro, tina, a seguir reproduzida, com alterasse gênero na América Lagișlação de vários paises dessa regiãoşões insignificantes, na le-

S.E.N.A. na Colômbia (Lei $n^{\circ} 118$ de 21 de junho de 1937).
N.A.T.I. no Peru (Lei n? 13.771 de 19 de dema S.E.N.A.T.I. no Peru (Lei $n^{\circ} 13.771$ de 19 de dezembro de 1961, I.N.C.E. na Venezuela (lei de 22 de agôsto de 1959), C.O.N.E.T. na Argentina, e assim por diante. $\left({ }^{*}\right)$

Foram imensos os serviçose prestados pelo S.E.N.A.I. à economia industrial bras leira na primeira, particularmente dificil e nevrálgica, fase de incipiente e rudimentar industrialização.

Contudo, uma vez trancorrido o perícdo de 21 anos de operação dessa entidade, verifica-se a necessicade imperiosa de revisão radical de suas técnicas de funcionamento, ora levada a efeito

$\left(^{\star}\right)$ Submetendo-se à análise a solução original brasileira no setor de aprendizagem, convém ressaltar que não diverge dos principios internacionalmente consagrados nessa matéria, e consubstanciados na Recomendação $\mathrm{n}^{\circ} 117$. aprovada pela Confe-ência Internacional do Trabalho em 25 de junho đe 1962 e na Recomendação, adotada pela $12^{\circ}$ sessão da Conferência Geral da
UNESCO, realizada entre 9 de novembro e 12 de dezembro de 1962 . 
pelo Departamento Nacional do S.E.N.A.I., eis que, particularmente, em virtude da sua limitada receita contributiva (adicional de apenas $1 \%$ sôbre a contribuição patronal previdenciária), não bastam mais para fazer face às crescentes necessidades pessoais do setor secundário da economia, em pleno ritmo de incremento horizontal e vertical.

A interpretação do sentido exato da atual e extremamente interessante revisão dos programas do S.E.N.A.I., seria difícil sem exame prévio dos princípios, que presidiram aos diplomas legais, relacionados com a constituição dessa entidade, criada por iniciativa da Confederação Nacional da Indústria, e administrada pelos órgãos especializados daquela organização suprema das classes produtoras da indústria.

Tais principios foram os cinco seguintes:

1. Devia servir para fomentar a formação da mão-de-obra, operária, preponderantemente semi-qualificada e qualificada, com certo desinterêsse manifestado em relação aos escalôes mais elevados, a serviço da indústria.

2. Atenção primacial devia ser prestada ao treinamento dos trabalhadores de menor idade, de qualquer modo, muito mais do que aos programas de formação profissional de adultos.

3. Supunha-se que tal objetivo podia ser conseguido, de melhor modo, mediante estruturação da instituição sócio-jurídica de aprendizagem industrial, aplicável a grupos etários de 14 a 18 anos, incentivando-se o recurso à mesma pelo setor patronal mediante redução, em metade, do salário-mínimo dos aprendizes, e obrigando-se, ademais, as emprêsas a admitirem ao emprêgo uma determinada cota mínima de jovens trabalhadores-aprendizes.

4. Partia-se, ao mesmo tempo, do pressuposto de que a aprendizagem dêsse grupo poderia ser assegurada, quase única $e$ exclusivamente, em escolas e cursos próprios do S.E.N.A.I., destinados a proporcionar formação profissional para determinados oficios e ocupações, mais comuns nas atividades manufatureiras. assim como em transportes, comunicações, etc.

5. Muito pelo contrário, nos respectivos diplomas lega's, estava sendo visivelmente relegado a lugar secundário, como modalidade apenas supletiva e complementar, a aprendizagem ministrada, diretamente, na órbita empresarial, prevendo-se apenas a isenção do pagamento de contribuições para o S.E.N.A.I. das emprêsas com particularmente extensas e adiantadas realizações nesse sentido.

Entretanto, tôdas essas assunções não encontraram corroboração integral nos resultados pragmáticos da ação desenvolvida pelo S.E.N.A.I. Com o tempo, verificou-se o crescente e angus- 
tiante hiato entre o vulto quantitativo das realizações técnico. educacionais dessa entidade e os efeitos práticos das obrigações normativas correlatas, acima aludidas, por um lado, e o tamanho das respectivas necessidades, inadiáveis e prementes, da indústria nacional, condizentes com a sua nova ordem de grandeza, por outra parte.

Não será fora de propósito ilustrar essas observações com algumas estimativas, quanto ao volume de mão-de-cbra industrial, cujo cômputo exato nos fornecerá a apuração final do Censo de 1960 , assim com indicações precisas, no tocante a serviços do S.E.N.A.I. e seu rendimento.

A mão-de-obra a serviço da indústria oscila, atualmente, em tôrno de 3 milhões de trabalhadores, dos quais, aproximadamente, um meio milhão de jovens trabalhadores menores de 18 anos.

Ora, o S.E.N.A.I. possuiu, em 1962, nada mais de 113 escolas com 805 cursos, nos quais se ensinava, mais ou menos, 108 ofícios, sendo que a matrícula geral em todos os tipos de cursos não ultrapassou a $33.305 \mathrm{e}$, quanto à matricula de menores de 14 a 18 anos, inscritos em cursos regulares de aprendizagem, a
22.198 pessoas.

$\mathrm{Na}$ última década nota-se crescimento pouco expressivo das escolas e dos cursos assim como das respectivas matrículas.

A luz do simples confronto entre o volume do pessoal empregado na indústria, discriminado em adultos e menores, e o número de matrículas que, aliás, não assegura, ainda, por si só, o término da aprendizagem, que, em virtude da evasão escolar, manifesta um grupo ainda mais restrito dos contemplados com cartas de ofício e certificados de aprendizagem, habilitação e conclusão - torna-se patente que o S.E.N.A.I., realiza no momento, tão sòmente uma parcela da grande tarefa que lhe é
confiada. $\left({ }^{\star}\right)$

Falharam também, de uma certo modo, várias premissas, que condicionaram a regulamentação que rege aspectos correlativos de emprêgo e salário dos jovens trabalhadores.

$\left(^{\star}\right)$ As mesmas distorções, particularmente graves no tocante à aprendiza. gem dos jovens trabalhadores, evidenciam-nos alguns dados relativos ao maior pelo Departamento Regional do S.E.N.A.I côrdo com o levantamento feito em 1961, 101.526 menores ocupados na ind do referido Estado havia ali. $10 \%$ do total, dos quais 60.872 exerceram tústria, isto é, quase exatamente interior de São Paulo. Ora, em consonância trabalho na capital e 40.654 no estavam matriculados em seus cursos veitavam o treinamento de aprendizagem no local 11.682 menores: e 17.551 apromenores não estavam enquadrados dentro local de trabalho. Assim, 72.293 ap:endizado, exercendo, em parte, ofícios que uma ou outra modalidade de dica, portanto trabalho não qualificado. 
Assim, por causa da lotação limitada das escolas e dos cur sos do S.E.N.A.I., tornaram-se, de fato, letra morta as normas, baixadas no sentido de determinar, aliás, de modo rígido e artificial, a proporção mínima de admissão dos aprendizes às emprêsas industriais.

Por sua vez, não foram coroadas de êxito as respectivas providências salariais. O tratamento garantido, nesse particular, aos aprendizes (redução global em 50\% das taxas de salário mínimo) sem estimular, em maior escala, o emprêgo dêles pelo setor patronal, contribui, porém, para desincentivar o interêsse dos menores por essa modalidade sui generis de trabalho, manifestando-se, no seu seio, preferência para o exercicio de ofícios e ocupações de nivel qualitativo baixo, que lhes garante direito à taxa integral de salário minimo. A falta de discriminação bastante acentuada entre os niveis da remuneração cabivel à mão-de-obra simples, não-qualificada e qualificada, efeito fatal da influência niveladora do salário-mínimo, cria, por seu turno, obstáculos à formação profissional, sob qualquer uma de suas formas, eis que encerra sacrificios em tempo, em esfôrço, até em dinheiro, que, a seguir, não encontram contrapartida na elevação dos padrões salariais.

Enfim, verifica-se, cada vez mais, a improcedência da politica de formação profissional que, (a) unilateralmente, beneficia apenas os trabalhadores menores, afinal de contas, sòmente uma minoria da classe trabalhadora e $(b)$ concentra todos os estorços no adestramento das camadas baixas, proletárias, sem tomar em devida consideração os programas de formação de pessoal médio e alto, capaz de contribuir, consideràvelmente, uma vez devidamente aperfeiçoado, para o treinamento dos grupos que lhe estão subordinados.

\section{IV}

Tal análise do balanço das realizações do S.E.N.A.I., orientada no sentido de legítima auto-critica, teve que levar à reformulação dos programas dessa entidade, consubstanciada nas proposições $n^{\circ} 11-15$, aprovadas pelo Conselho Nacional do S.E.N.A.I.. em março de 1963.

O que se objetiva nelas é, em última análise:

a) a ênfase às atribuições do S.E.N.A.I., como órgão de promoção de mão-de-obra industrial, com equivalentes objetivos econômicos e sociais, sem a sua configuração como uma parcela do sistema educacional do País;

b) utilização mais eficiente das escolas existentes, evitando-se a excessiva e injustificada ampliação da sua rêde atual e promo- 
vendo-se, onde e quando fôr considerado oportuno, a transformação dêsses estabelecimentos em centros dinâmicos de treinamento, afastados da tradicional e ortodoxa indole escolar;

c) maior desenvolvimento de programas de treinamento nas emprêsas, que, dada a sua natureza eminentemente prática e vinculada com as necessidades especificas de operação das respectivas indústrias, oferece oportunidades lisonjeiras, que, todavia, deverá ser assessorado e orientado pelo S.E.N.A.I., inclusive mediante acôrdos de colaboração, celebrados entre as mesmas e êsse Serviço, subordinando-se a aplicação direta pela emprêsa das contribuições, devidas ao S.E.N.A.I., ao preenchimento de tôda uma série de exigências;

d) extensão paulatina da órbita pessoal do S.E.N.A.I., para que as suas atividades possam abranger, com o correr do tempo, tôdas as faixas etárias e todos os escalões de mão-de-obra de nível básico, de pessoal de supervisão técnica pròpriamente dito e de direção;

e) colaboração estreita e permanente, nesse setor, do S.E.N.A.I. com escolas de ensino técnico, médio e superior, assim como tôdas as demais entidades interessadas nessa matéria;

f) contribuição ativa do S.E.N.A.I. por ocasião da substituição do C.L.T. pelo Código de Trabalho $\left({ }^{*}\right)$ para a revisão dạ atual regulamentação normativa da figura de aprendizagem, no intuito de escoimá-la de todos os defeitos acima apontados; e,
enfim;

g) reestruturação administrativa do S.E.N.A.I., para que possa assumir tôdas as novas obrigações acima aludidas, com redefinição das atribuições cabiveis, respectivamente, ao Departamento Nacional e aos Departamentos Regionais.

O sentido dessas importantes alterações, que encontram reflexo nas conclusões do Seminário Nacional de Diretores Regionais do S.E.N.A.I. (Pati do Alferes, 1 de junho de 1963), parece tão claro que dispensa quaisquer comentários adicionais.

Parece-nos apenas desejável acrescentar algumas observações necessárias para esclarecer melhor a orientação consubstanciada
nos itens a) e c).

A própria essência da aprendizagem continua ainda, entre nós, objeto da interpretação bastante controvertida. Com efeito, opõem-se, na apreciação dêsse assunto, uma à outra, duas teses opostas. Uma que lhe atribui indole de arma de educação "in-

$\left(^{*}\right)$ Cumpre examinar o Anteprojeto de Código de Trabalho, de autoria do Prof. Evaristo de Morais Filho, apresentado, em 31 de março de 1963. ao Sr. Ministro da Justiça e Negócios Interiores, que, aliás, na Seção V ("Da Aprendizagem") do Capitulo III do Titulo IV. muito se afasta das diretrizes, acima fo-muladas e pleiteadas pelo S.E.N.A.I. 
tegral", e outra que vê nela "instrumento a serviço do desenvolvimento econômico e social". A primeira, advogada pelo S.E.N.A.C. $\left({ }^{\star *}\right)$ e a segunda, preconizada pelo S.E|N.A.I.

Em consonância com os preceitos doutrinários, pleiteados pelo S.E.N.A.C., a formação profissional dos menores deveria constituir "um conjunto de objetivos morais, civicos, intelectuais e profissionais, que se completam num todo indissolúvel a colimar, "devendo, por conseguinte, os programas dos respectivos serviços "ser elaborados, precipuamente, em função dos interêsses gerais da educação nacional, e não nos dos interêsses privados da economia empresarial".

Porque o S.E.N.A.I. discorda dessa conceituação? Evidentemente, não pode ignorar nem menosprezar a enorme relevância, de que se reveste, no cenário do Brasil de 1963, a educação geral. Entretanto, parte do pressuposto, conforme que a contribuição, para êsse fim, dos cursos de aprendizagem, aliás com matricula relativamente reduzidissima, não possa constituir, mesmo na melhor das hipóteses, mais do que subproduto, pouco expressivo, de suas atividades. Por conseguinte, de acôrdo com o princípio salutar de divisão de trabalho, é a rêde nacional escolar que deveria, no modo de ver do S.E.N.A.I., competir, com exclusividade, o cumprimento de tal importante tarefa, evitando-se, assim, a deturpação do caráter genuino da aprendizagem, instrumento sui generis, destinado a promover o progresso econômico e social. A bifurcação dispersiva de atividades dirigidas, simultâneamente, num e noutro sentido, levaria a resultados nitidamente insatisfatórios, encarados sob êsses dois prismas. Seria, pois, preferivel que os Serviços de Aprendizagem concentrassem todos seus esforços na organização da formação profissional, pròpriamente dita, de relevância crucial, e em que atuam quase monopolisticamente, sem pretenderem cumprir, ao mesmo tempo. tarefas meramente educacionais, para cujo desempenho não estão devidamente preparados, e para as quais não foram criados. Por conseguinte, os órgãos representativos do S.E.N.A.I., consideram oportuno descarregar a rêde de cursos de aprendizagem das atribuições vinculadas ao campo de instrução formal, suprimindo-se ou reduzindo-se ao mínimo o estudo das disciplinas essenciais à escolaridade geral, e depurando-se seus estabelecimentos da indole clássica e ortodoxa escolar. Muito pelo contrário, tudo deverá ser feito para subordinar às exigências tecnológicas especificas do setor empresarial, público ou privado, as mais discriminadas e individualizadas, peculiares de cada um de seus res-

(**) Prof. Roberto N. Dannemann "Trabalho do Menor Aprendiz e sua formação profissional Mietódica, Estudo e Projeto de Decreto" Rio de Janeiro, abril de 1962. 
pectivos ramos e, até de cada uma emprêsa, considerada em si só, os programas de formação profissional, inclusive de aprendizagem.

Essa controvérsia, que, aliás, indiretamente, reflete certa disparidade entre as necessidades da indústria e do comércio, quanto ao treinamento do pessoal a seu serviço, não pode deixar de repercutir, por seu turno, sôbre a opção entre várias técnicas de formação profissional, que se oferecem aos referidos dois Serviços de Aprendizagem.

Dentro da conceituação rigorosamente econômica, defendida pelo S.E.N.A.I., têm que ocupar posição de maior relêvo os programas de treinamento no próprio emprêgo, dentro da órbita infra-empresarial, nos quais, por motivo óbvio, não se pode emprestar maior importância aos deveres relacionados com as metas de "educação integral dos trabalhadores". Com efeito, pode-se antecipar que a emprêsa moderna e bem organizada sabe apreciar as necessidades, no tocante ao treinamento do pessoal que ocupa, de modo incomparàvelmente melhor do qúe quaisquer organizações externas. Dentro da emprêsa, a formação profissional e aprendizagem adquirem caráter dinâmico, entrelaçado com as demais providências racionalizadoras patronais (seleção e recrutamento, promoção, estruturação objetiva do sistema salarial, serviços sociais, relações humanas etc.) $\left({ }^{\star}\right)$ visando a elevação máxima dos indices de produtividade mediante aumento da sua parcela, particularmente relevante, ligada ao rendimento do trabalho. O treinamento, no local de trabalho tem sempre cunho acentuadamente prático, muito mais econômico do que o "institucional", não acusa taxas de "evasão" e obedece, de modo flexível e plástico, aos requisitos variáveis da economia empresa-
rial.

Entretanto, a ênfase deslocada para o fomento dos respectivos programas microempresariais não significa de modo algum, contràriamente ao que se possa pensar à primeira vista, diminuição das diretas responsabilidades funcionais do S.E.N.A.I. nessa matéria. Apenas, como é natural, sofrem alterações, no que diz respeito às obrigações, relacionadas com o nôvo papel que essa entidade passa a desempenhar junto às emprêsas, determinadas a enveredar nesse caminho.

Tem que lhes prestar assessoramento. Tem que se encar regar da formação do pessoal de grau médio, particularmente, instrutores, mestres, e contra-mestres industriais, aos quais caberá ministrar, a seguir, treinamento ao operariado dentro da emprêsa.

$\left(^{\star}\right)$ Convém consultar Tomás DE VILLAnova M. Lopes, Problemas de Administração da Emprêsa Moderna. Fundação Getúlio Vargas, 1963. 
Tem que fornecer aos respectivos serviços empresariais material didático e instruções técnicas de que possam precisar. Tem que completar, onde e quando fôr necessário, a formação e aprendizagem profissional, essencialmente prática, assim organizada, mediante ensino supletivo, destinado a proporcionar aos formandos alguns elementares conhecimentos teóricos. Tem que conceder ajuda técnica e administrativa ao setor empresarial na seleção adequada pelo mesmo dos programas que se possam coadunar, de melhor modo possivel, com os objetivos colimados. Eis apenas alguns exemplos isolados da assistência de grande valor, que o S.E.N.A.I., pode e deve prestar à economia microempresarial, para facilitá-la a enfrentar tarefas, de grande responsabilidade, que ora assume.

Os principios de frutuosa colaboração sistemática acima esboçada têm que encontrar reflexos em acôrdos celebrados entre essa entidade e as emprêsas, nos quais, de ora em diante, não se concede, mais o direito de aplicação direta da contribuição devida ao S.E.N.A.I., a não ser em base de compromissos firmes patronais, no tocante à programação satisfatória da formação profissional e aprendizagem infraempresarial. Tais acôrdos definem as modalidades das respectivas atividades, os grupos beneficiados, os fundos específicos, destinados a tal fim. os órgãos da emprêsa, encarregados da aplicação dêsses programas, os gastos anuais com os mesmos etc., outorgando-se, ao mesmo tempo, à referida entidade direitos necessários à fiscalização da execução dêsses entendimentos.

São relativamente poucos os setores da economia, que não oferecem maiores perspectivas, quanto ao recurso a essa fórmula interessante de treinamento profissional, que merece, no estrangeiro, tratamento preferencial. São, antes de mais nada, indústrias pequenas e flutuantes, como seja, p. ex., a construção civil. Por outro lado, dificilmente prestam-se à aplicação generalizada dessa modalidade, na maior escala, as atividades comerciais, o que explica a atitude, um tanto divergente do ponto-de-vista do S.E.N.A.I., tomada, nesse particular, pelo S.E.N.A.C.

Nessas condições, nada se oporia a um certo divorciamento das soluções normativas, no momento quase homogêneas, que passariam a reger, futuramente, de modo diferente a aprendizagem industrial e comercial.

Não procederia a opinião, conforme que os programas de formação, deslocados para o treinamento no próprio local de trabalho, no propósito de lhes assegurar maior amplitude e eficiência, assim como ritmo mais acelerado, possam levar à sua subordinação unilateral as decisões arbitrárias dos empregadores. Tais desvios ficam, de ante-mão, anulados pela posição de destaque, reservado, dentro do referido mecanismo contratual, ao S.E.N.A.I. 
Outrossim, cogita-se da criação de Comissões operárias de Formação Profissional, às quais caberiam em emprêsas de vulto médio e grande atribuições análogas às desempenhadas por órgãos congêneres ("CIPA") no setor de segurança de trabalho.

A reforma funcional acima esboçada e que se processa, no momento, simultâneamente, mais ou menos no mesmo sentido, em todos os paises industrializados, acarretará, fatalmente, a revisão do conjunto de normas relativas a êsse assunto, atualmente consubstanciadas ha C.L.T. e em numerosos diplomas legais, aplicáveis à aprendizagem. Às diretrizes dessa reforma não corresponde o supra-mencionado Ante-Projeto de Código de Trabalho, de orientação ortodoxa e tradicional, devendo, pois, os respectivos dispositivos ser cuidadosamente reexaminados para reajustá-los aos novos rumos de formação profissional.

Finalizando êste sucinto resumo, desejamos, ainda ressaltar os serviços de elevado valor que nos poderá prestar, nessa matéria, o Centro de Documentação e Intercâmbio em Formação Profissional na América Latina (Cinterfor), cuja criação foi deliberada pela Segunda Reunião Técnica Preparatória, convocada pela O.I.T., e realizada no Rio de Janeiro, de 24 de junho a 2 de julho de 1963. $\left({ }^{*}\right)$

Quer nos parecer que tudo o que precede manifesta, desde já, a magnitude e complexidade dos problemas de formação profissional, que deverão ser atacados e equacionados, com urgência, eis que, de contrário, a manutenção passiva do Statu Quo encerraria os mais graves riscos econômicos e sociais.

Todos os aspectos qualitativos de mão-de-obra não podem ser, todavia, artificialmente separados de suas facetas quantitativas, isto é do emprêgo, desemprêgo e subemprêgo.

Seja como fôr, não pode ser mais protelado o início da dinâmica política nacional de mão-de-obra, com o objetivo principal de valorização máxima dos recursos humanos, dentro do estado ideal de "pleno emprêgo".

O primeiro passo nesse sentido deverá constituir-se - convém repeti-lo mais uma vez - a criação, na estrutura administrativa federal, de um órgão central, dotado de poderes amplos e incisivos nesse particular.

A reforma da administração, ora levada a efeito, seria manifestamente incompleta, se - em oposição às realizações dessa indole, adotadas por quase todos os paises de ordem de grandeza do Brasil - não fôsse extensiva ao preenchimento da referida e grave lacuna no atual organograma dos serviços públicos federais.

A abundante experiência, acumulada com o funcionamento do Mercado Comum Europeu, permite antecipar que a consoli-

(*) Co:reio do S.E.N.A.I. $\mathrm{n}^{\bullet}$ 245, de julho de 1963. 
dação do Mercado Comum Latino Americano, cuja organização inicial e precursora constitui a ALALC, fará com que assumirão importância ainda muito maior programas interamericanos, relacionados com a intensificação da formação profissional, como, aliás, também com o fomento do livre intercâmbio, entre os países participantes, não sòmente de capital e de bens, como também de mão-de-obra de elevado valor vocacional. $\left({ }^{\star}\right)$

Tal estado maior da administração de mão-de-obra, órgão de alto gabarito hierárquico - p. ex-Departamento Nacional de Mão-de-Obra, encaixado na órbita do Ministério do Trabalho e Previdência Social - não corresponderia às suas imensas responsabilidades, se não fôssem incluídos na sua alçada assuntos relacionados com a orientação e contrôle dos programas de formação profissional, inclusive funções cocrdenadoras no tocante à respectiva rêde escolar, com o serviço de emprêgo $\left({ }^{\star \star}\right)$ e com a regulamentação das migrações internas e da imigração internacional, devendo caber-lhe, ademais, posição de célula, encarregada de planejamento plurianual econômico-social, quanto à utilização integral de mão-de-obra.

A consciência, ùltimamente já muito amadurecida, quanto aos tremendos desperdícios na valorização, apenas parcial e ineficiente, tanto anti-econômica, quanto anti-social, dos recursos humanos - afinal de contas, principal elemento da riqueza nacional? - torna imperiosas tôdas essas providências racionalizadoras e disciplinadoras.

Não nos iludamos: A reestruturação administrativa acima pleiteada não passará, por si só, de solução de mera fachada, de significado pouco expressivo. Acontece, todavia, que sem criação prévia de tal nôvo órgão público não será possivel preencher, a seguir, todos os insuportáveis claros que se nos oferecem nessa relevante matéria.

(*) Convém consultar Valorização dos Recursos Humanos, relatório apresentado em setembro de 1963, pela Confederação Nacional da Indústria ao II Congresso da AILA.

$\left(^{\star \star}\right)$ Não nos foi, ainda, possivel cumprir os compromissos, claros e inequivocos, que assumimos nessa matéria, quanto à organização do Serviço Nacional de Emprêgo, mediante ratificação da convenção internacional de trabalho $\mathrm{n}^{\circ} 88$. 